\title{
Hubert BOST, Pierre Bayle historien, critique et moraliste
}

Bibliothèque de l'École des Hautes Études, Sciences religieuses, vol. 129, Turnhout, Brepols Publishers, 2006, 276 p., ISBN 2-503-52340-4, $35 €$.

\section{Raymonde Monnier}

\section{(2) OpenEdition \\ 1 Journals}

Édition électronique

URL : https://journals.openedition.org/ahrf/11263

DOI : $10.4000 /$ ahrf. 11263

ISSN : 1952-403X

Éditeur :

Armand Colin, Société des études robespierristes

Édition imprimée

Date de publication : 1 septembre 2007

Pagination : 203-205

ISSN : 0003-4436

Référence électronique

Raymonde Monnier, "Hubert BOST, Pierre Bayle historien, critique et moraliste », Annales historiques de la Révolution française [En ligne], 349 | juillet-septembre 2007, mis en ligne le 29 décembre 2009, consulté le 01 juillet 2021. URL : http://journals.openedition.org/ahrf/11263 ; DOI : https://doi.org/10.4000/ ahrf. 11263 


\section{$\begin{array}{llllllllllllllllllllll}C & O & M & P & T & E & S & R & E & N & D & U & S\end{array}$}

Hubert Bost, Pierre Bayle historien, critique et moraliste, Bibliothèque de l'École des Hautes Études, Sciences religieuses, vol. 129, Turnhout, Brepols Publishers, 2006, 276 p., ISBN 2-503-52340-4, $35 €$.

L'œuvre de Pierre Bayle (1647-1706), cet « intellectuel » avant la lettre dont l'influence a été considérable dans l'Europe des Lumières, continue de faire l'objet de nombreuses publications en France et à l'étranger. Pour le troisième centenaire de sa mort, Hubert Bost, grand spécialiste du protestantisme, notamment de la pensée et de la figure complexe de l'auteur du célèbre Dictionnaire, a déjà publié en 2006 un ouvrage d'une érudition exigeante (Pierre Bayle, Fayard, 696 p.), qui revisite profondément les études bayliennes sur la base de nouvelles ressources archivistiques. Le présent livre apporte différents points de vue, au plus près des questionnements, des échanges intellectuels et de l'évolution de la pensée du philosophe de Rotterdam, qui éclairent et prolongent la biographie intellectuelle présentée dans le premier ouvrage. Il rassemble en quatre grands chapitres, augmentés d'une bibliographie et d'index, une quinzaine d'études publiées de 1990 à 2006 dans des revues ou actes de colloques (deux sont inédites), sur la méthode et la position de Bayle dans les questions et les controverses de son tcmps. Que penser des mythes et croyances, des faux prophètes et de la notion d'hérésie (I- Croyances, crédulité, enthousiasme) ? Comment le « journaliste » Bayle est-il passé maître dans l'acte de lire, activité à la fois ludique et sérieuse d'une pensée toujours en déplacement (II- Journalisme et philosophie de la lecture) ? Sur quelle méthode, quelles stratégies et quels arguments construit-il ses dossiers croisés d'histoire religieuse (IIIDossiers d'histoire religieuse) ? De quelles conceptions éthiques et politiques procède chez lui l'affirmation centrale du principe de tolérance (IV- Une éthique de la tolérance, entre obéissance et liberté de conscience) ? Lauteur rappelle d'entrée de jeu que Bayle, qui a enseigné la philosophie et l'histoirc à l'illustre École de Rotterdam pendant une douzaine d'années, « ne s'est jamais coulé dans le moule du discours philosophique stricto sensu », et s'est préoccupé également de l'examen des faits et de l'histoire de son temps. Sa pensée critique singulière recourt à différents genres littéraires pour dialoguer avec autrui - la correspondance, le journal, le pamphlet, le dictionnaire - pour analyser les faits, contourner ou subvertir l'argumentaire adverse, convaincre ses lecteurs en croisant les considérations morales, théologiques ou politiques. C'est de a cctte pensée fragmentaire et sinueuse qui se refuse au système et préfère toujours les questions aux réponses ", que son recucil d'études entend rendre compte.

En démontant l'histoire sans queue ni tête de la comc̀te présageant les malheurs des hommes, dans ses Pensées diverses sur la comète, Bayle entreprend la critique plus générale des mythes astrologiques. Parcourant divers champs de l'his- 
toire, de la science, de la philosophie et de la théologie, il va jusqu'à contribuer de façon radicale " au salutaire désenchantement du ciel " : la définition d'un signe ne peut être pertinente que s'il existe une intention de signifier, humaine ou divine. Quand il traite des fanatiques et des faux prophètes, il a soin de distinguer entre le fanatique sincère ou le visionnaire aveuglé ( $\mathrm{H}$. Bost risque l'oxymore), et le faux prophète qui calcule, l'imposteur qui joue à l'inspiré - distinction qui se précise au long des articles du Dictionnaire. Il faut dénoncer les imposteurs et montrer les erreurs des fanatiques afin d'éviter la contagion générale. Mais comment faire la part des choses entre croyance et crédulité ? comment se préserver des dangers du fanatisme sans mettre en cause les droits fondamentaux de la conscience errante ? Sa brève conversion au catholicisme, avant de revenir à la religion des siens, lui a fait vivre très jeune l'épreuve du doute. Pour Bayle, la notion même d'hérésie a quelque chose de problématique ; son usage abusif en affaiblit le sens. Comme chez Milton avant lui, la question des hérétiques débouche sur le refus des sectarismes et une apologie de la tolérance, seule compatible avec les exigences de la foi évangélique et de la raison philosophique.

Cet idéal de tolérance ne peut se déployer que dans un espace de liberté de penser reconnue à tous. $\mathrm{Ce}$ qui introduit à la question du rapport du politique et du religieux, traité dans la quatrième partie avec un chapitre inédit : "Bayle entre droit et religion. Obligation de conscience et obéissance civile ». La violence et l'intolérance étant le propre de l'homme - l'histoire du christianisme nourrit son pessimisme anthropologique - Bayle adopte une position réaliste en défendant la pluralité religieuse garantie par l'État, mais contre toute coercition en matière de conscience. Le principe de réciprocité renverse le schéma officiel de la pratique missionnaire, dans une perspective qui suspend la question de l'orthodoxie et défend les droits de la conscience errante. Toute illusion sur le politique tombe devant les arrêts contre les protestants qui témoignent de méthodes " obliques": "Lair de grandeur est mieux imprimé dans les qualitez du lion que dans celles du renard ». Sans dénier la souveraineté monarchique, Bayle, en opposant légalité juridique et légitimité morale, "sacralise la conscience individuelle et lui restitue une capacité de décision, qu'aucun pouvoir fut-il tyrannique, ne saurait lui retirer » (p. 222). Grotius, Bodin et Hobbes lui ont donné les outils théoriques pour étayer son approche de l'obéissance civile et de l'obligation de conscience sur la base de ses convictions théologiques et de ses connaissances historiques, et poser en raison les limites de l'intervention politique.

La question de l'écriture de l'histoire, celle du christianisme en général et celle de la Réforme en particulier, a préoccupé Bayle tout au long de son ocuvre, de la Critique générale de l'Histoire du calvinisme de Mr Maimbourg (1682), pour réfuter une histoire partisane, à l'Avis aux réfugiés (1690), qu'il a dû patronner s'il ne l'a écrit, et au Dictionnaire historique et critique, en passant par l'examen des questions touchant les protestants et les Églises réformécs de France dans les Nouvelles de la République des Lettres (1684-1687). Les guerres de religion et le problème de la violence tiennent une place importante dans sa réflexion sur l'histoire de France. Dans la Critique générale, il combat Maimbourg sur son propre terrain, en mettant à jour les contradictions, le défaut de preuves et la collusion du discours avec le pouvoir politiquc. Lintention est double et prête à deux niveaux de lecture, faire connaître à tous ses lecteurs l'histoire du protestantisme français et ses principales figures, s'adresser aux protestants du Refuge pour qu'ils se gardent de toute interprétation mythique de leur histoire. Qu'il traite les questions par l'argumentation 
logique ou par l'ironie, ce qui importe est d'évaluer la part d'idéologie, dans une recherche de la vérité historique qui récuse le discours partisan et l'hypocrisie du discours du pouvoir. Bayle joue sur différents registres, entre réflexion philosophique, engagement journalistique et mobilisation sur le terrain, dans une approche originale de l'histoire qui répond à une expérience vécue et combine identité protestante et critique historique. Face à l'exclusion qui s'abat sur les Églises réformées de France, il démonte la " mystification sémantique " et la corruption du langage qui autorise la répression. Quand la Glorieuse Révolution d'Angleterre devient un enjeu interne au Refuge (XII. Un exemple d'" histoire immédiate »), son regard se décompose en une multitude de facettes; il n'a pas d'illusions sur les motivations des "révolutions" politiques, et se montre inquiet comme protestant du Refuge de la menace qu'un soutien prononcé de ses coreligionnaires fait peser sur leurs chances de retour en France.

Le corpus de ses articles dans les Nouvelles de la République des Lettres, qui vise un public étendu au delà du cercle des savants, fournit une information très riche sur la production livresque en Europe, l'intensité des questions religieuses qui atteint son paroxysme avec la révocation de l'Édit de Nantes, le poids énorme des controverses doctrinales qui traversent toutes les disciplines. Bayle écrit en médiateur culturel, soucieux d'impartialité et tire la leçon de la méthode de Descartes pour débusquer l'erreur : «Il n'y a point de prescription contre la vérité : les erreurs pour être vieilles, n'en sont pas meilleures » (VI. Diffusion et discussion du cartésianisme). Léthique de l'examen conforte la critique protestante de la tradition. Le chapitre VII propose une interprétation très stimulante de l'acte de lecture chez Bayle, véritable vocation à visée pédagogique. Il montre comment la diversité des thèmes, la relation dialogique avec les lecteurs d'une "république des lettres " idéale, mettent en jeu de façon permanente un réseau de complicité qui se nourrit de la passion insatiable du lire : le lego baylien, qu'Hubert Bost propose en regard du cogito cartésien et définit comme « le jeu raffiné de lectures et d'écritures emboîtées ", ressemble à un jeu de constructions et de déconstructions infinies, celui d'une pensée en évolution constante en mesure de créer un mode d'être au monde.

En suivant Bayle au détour de ses raisons et de ses questions, de ses positions dans les grandes batailles de son temps, Hubert Bost nous donne à lire un ouvrage dense sur l'émergence de conceptions radicalement nouvelles sur le rapport du politique et du religieux, sur la tolérance, les sphères distinctes du privé et du public. «Le but poursuivi, écrit-il en introduction, est de montrer que cette pensée qui résiste aux étiquettes est traversée de préoccupations qui, loin d'être abstraites, sont toujours en prise avec les défis de son époque ». Le philosophe s'efforce à travers ses écrits à apprendre aux hommes à s'émanciper des préjugés pour examiner eux-mêmes les faits et les discours dominants. Ce qui donne à ses réflexions, en un temps où la question théologico-politique se pose avec acuité à l'échelle du monde, une surprenante actualité.

Raymonde MONNIER 